\title{
Quantifying the orbital contribution in the "Spodium Bond" via Natural Orbital for Chemical Valence-Charge Displacement analysis
}

Gianluca Ciancaleoni, ${ }^{\mathrm{a}}$ Luca Rocchigiani ${ }^{\mathrm{b}}$

${ }^{a}$ Università degli Studi di Pisa, Dipartimento di Chimica e Chimica Industriale, via Giuseppe Moruzzi 13, 56124 Pisa, Italy. E-mail: gianluca.ciancaleoni@ unipi.it

${ }^{\mathrm{b}}$ School of Chemistry, University of East Anglia, Norwich Research Park, NR4 7TJ, Norwich, UK. Email: 1.rocchigiani@uea.ac.uk

\section{Abstract}

\section{Introduction}

$\sigma$-hole bonding, ${ }^{1}$ i.e. the attractive interaction between a polarised main group atom and a Lewis base (LB), is gaining considerable importance within the family of non-covalent interactions. It arises from an anisotropic charge distribution around the polarised atom, which creates a region of positive electrostatic potential ( $\sigma$-hole) interacting with electron-rich moieties. The most notable example is the halogen bond $(\mathrm{XB}),{ }^{2-4}$ which is increasingly establishing as a versatile tool in crystal engineering, catalysis and photoluminescence. ${ }^{3}$ More recently, the " $\sigma$-hole interactions" family has been expanding throughout the periodic table to chalcogen $(\mathrm{ChB}),{ }^{5-8}$ pnictogen $(\mathrm{PB}){ }^{9}$ and tetrel bond (TB) ${ }^{10}$ Along with the latter, $\pi$-hole interactions demonstrated to be worth of attention. ${ }^{11,12}$

The latest addition to this group is the metal bond, which entails systems where a $\sigma$-hole is localised on a transition metal having a completely filled $d$ shell. For example, in the case of group 11 metals, the "coinage metal-bond" has been proposed for the mainly electrostatic interaction between a polarized metal (as $\mathrm{CuCl}$ or $\mathrm{AgCl}$ ) and a $\mathrm{LB},{ }^{13,14}$ even if some authors push for a more concise and general nomenclature, ${ }^{15}$ recognizing the common nature of all these weak interactions. Joy and Jemmis underlined that a LB $\rightarrow$ M polarization is possible only for metals having a completely filled $d$ shell, whereas for others, as rhodium and cobalt for instance, a M $\rightarrow$ LB polarization prevails. ${ }^{16}$ An interesting case is that of group 12 metals, for which the capability of forming the so-called "spodium bond" ( $\mathrm{SpB}$ ) has been proposed. ${ }^{17}$ In a very recent contribution, Frontera et al. analysed a series of 
[(thiourea $\left.)_{2} \mathrm{MX}_{2}\right]$ complexes $(\mathrm{M}=\mathrm{Zn}, \mathrm{Cd}, \mathrm{Hg} ; \mathrm{X}=\mathrm{Cl}, \mathrm{Br}, \mathrm{I})$ and revealed that $\sigma$-holes located along the bisector of the S-M-S bond can establish weak, non-coordinative interactions with moderate LBs such as $\mathrm{CO}, \mathrm{CH}_{3} \mathrm{CN}$ or $\mathrm{CH}_{2} \mathrm{O} .{ }^{18}$ Such model adducts generally show the concomitant presence of a series of weak interactions, including hydrogen (HB) and chalcogen bonds, as evidenced by the quantum theory of atoms in molecules (QTAIM). Since they all contribute to the overall fragment interaction energy, it is important to disentangle these contributions to provide a precise assessment of the importance of SpB. A recent theoretical and detailed work used the Energy Decomposition Analysis (EDA) ${ }^{19,20}$ and other tools on $\mathrm{HgCl}_{2} \cdots \mathrm{LB}$ adducts, highlighting that the latter are held together by a coexistence of the electrostatic $\left(E_{\text {elst }}\right)$ and orbital $\left(E_{\text {orb }}\right)$ terms. ${ }^{21}$ The ratio $E_{\text {orb }} /($ sum of all the attractive forces) spans from 20 to $30 \%$. Still, it would be interesting to better understand what is the role of the $\mathrm{SpB}$ in the $\mathrm{E}_{\text {orb }}$ term, that is a net charge transfer from the filled orbitals of the LB to the empty $\sigma^{*}(\mathrm{M}-\mathrm{X})$ orbital.

In order to do this, we decided to characterize the same adducts of the Frontera's work (Scheme 1) by Natural Orbital for Chemical Valence (NOCV) ${ }^{22,23}$-Charge Displacement (CD) ${ }^{24-26}$ analysis, which recently proved to be perfectly able in the characterization of adducts held by multiple interactions. ${ }^{27-31}$

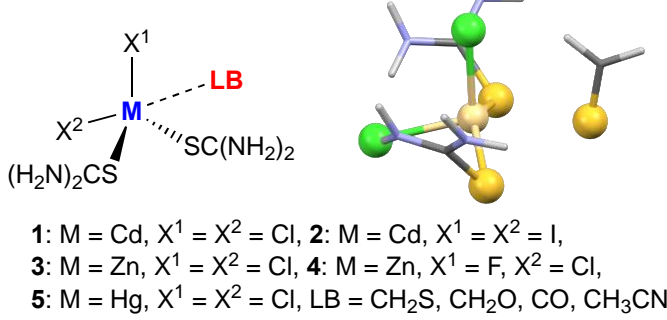

Scheme 1. Numbering of the complexes studied and optimized structure of $\mathbf{1 C H}_{2} \mathrm{~S}$.

Further, the inspection of crystal structures deposited at the Cambridge Crystallographic Data Centre (CCDC) reveals the existence of a number of structures of group 12 compounds showing intermolecular M $\cdots$ LB distances shorter than the sum of the corresponding van der Waals radii in the solid-state. ${ }^{18}$ But in all the cases many interactions are potentially active. One could think that all of them belongs to the $\mathrm{SpB}$ category, but this is not obvious, especially from the orbital point of view. Also in these cases the separation and quantification of the different interactions are necessary for the in-depth comprehension and characterization of the adducts. Therefore, we selected some experimentally characterized structures, we isolated the adducts hypothetically involved in a SpB and we applied both the EDA and the NOCV$\mathrm{CD}$ analyses. 
Our results shows that: i) from the methodological point of view, the NOCV-CD analysis is often able to perfectly separate and quantify the different interactions between two fragments, both in terms of energy and amount of electron density involved: and ii) the spatial proximity between a polarised group 12 metal and a LB does not automatically imply the presence of an "orbital" SpB.

\section{Results and discussion}

Model 1CH2S system. NOCV-CD and EDA calculations on model complexes 1-5 (Scheme 1) with different Lewis bases $\left(\mathrm{CH}_{2} \mathrm{~S}, \mathrm{CH}_{2} \mathrm{O}, \mathrm{CO}\right.$ and $\left.\mathrm{CH}_{3} \mathrm{CN}\right)$ were performed at the M06-D3/TZVP/ZORA level ${ }^{16}$ (see Computational Details). Starting with $\mathbf{1} \mathbf{C H}_{2} \mathbf{S}$, we observed that the total interaction energy ( $\left.\mathrm{E}_{\text {int }}\right)$ between 1 and $\mathrm{CH}_{2} \mathrm{~S}$ amounts to $-10.5 \mathrm{kcal} / \mathrm{mol}$ and it is composed by a steric energy $\left(\mathrm{E}_{\mathrm{st}}=\right.$ Pauli repulsive term $E_{\text {Pauli }}+$ electrostatic term $E_{\text {elst }}$ ) of $2.2 \mathrm{kcal} / \mathrm{mol}$, a dispersion energy of $-0.9 \mathrm{kcal} / \mathrm{mol}$ and a considerable orbital contribution $\left(\mathrm{E}_{\mathrm{orb}}\right)$ of $-11.8 \mathrm{kcal} / \mathrm{mol}$ (Table 1). Keeping the geometry fixed and using many different fucntionals, it appears evident that $\mathrm{E}_{\text {orb }}$ shows to be quite stable and between 11.7 and $13.0 \mathrm{kcal} / \mathrm{mol}$ (Table 1). The largest deviation is given by the double hybrid B2PLYP functional that leads to a slightly smaller value $(-10.0 \mathrm{kcal} / \mathrm{mol})$. Regarding the basis set, it is important to use an adequate large one, as $E_{\text {orb }}$ is over-estimated when a small basis set (sVP) is used. The differences in the dispersion term $\left(\mathrm{E}_{\mathrm{disp}}\right)$ are due to the different corrections used (in ORCA 4.1.0, M06 functional comes only with the D0 correction).

Table 1. Dependence of EDA results with functional/basis set for $\mathbf{1 C} \mathbf{C H}_{2} \mathrm{~S}$.

\begin{tabular}{lllll}
\hline Functional/basis set & $\mathrm{E}_{\text {int }}$ & $\mathrm{E}_{\text {orb }}$ & $\mathrm{E}_{\text {st }}$ & $\mathrm{E}_{\text {disp }}$ \\
\hline M06-D0/ZORA-TZVP & -10.5 & -11.8 & 2.2 & -0.9 \\
B3LYP-D3/ZORA-TZVP & -10.0 & -11.7 & 9.4 & -7.6 \\
PBE0-D3/ZORA-TZVP & -10.3 & -11.7 & 5.6 & -4.3 \\
TPSSh-D3/ZORA-TZVP & -10.8 & -12.3 & 7.2 & -5.7 \\
TPSS-D3/ZORA-TZVP & -10.8 & -13.0 & 8.0 & -5.8 \\
BLYP-D3/ZORA-TZVP & -10.1 & -13.1 & 12.1 & -9.1 \\
BP86-D3/ZORA-TZVP & -12.5 & -13.4 & 9.3 & -8.3 \\
B2PLYP-D3/ZORA-TZVP & -9.1 & -10.0 & 5.0 & -4.0 \\
B3LYP-D3/ZORA-sVP & -14.6 & -15.8 & 8.9 & -7.6 \\
BP86-D3/ZORA-sVP & -16.9 & -17.8 & 9.3 & -8.3 \\
\hline
\end{tabular}


The decomposition of $\mathrm{E}_{\mathrm{st}}$ in $\mathrm{E}_{\text {Pauli }}$ and $\mathrm{E}_{\mathrm{elst}}$, which is not possible with ORCA 4.1.0, can be done with ADF, leading (using B3LYP-D3, ZORA and TZ2P basis set) to the following results: $\mathrm{E}_{\text {int }}=$ $-8.6, \mathrm{E}_{\text {orb }}=-12.3, \mathrm{E}_{\text {Pauli }}=39.0, \mathrm{E}_{\mathrm{elst}}=-27.7$ and $\mathrm{E}_{\mathrm{disp}}=-7.6 \mathrm{kcal} / \mathrm{mol}$. Noteworthy, the value of $E_{\text {orb }}$ is similar to that obtained with ORCA, whereas $E_{\text {int }}$ is smaller. The complete decomposition shows that the electrostatic component is very relevant, as it happens with all the $\sigma$-hole interactions. The orbital term is about $25 \%$ of all the attractive forces.

A visual inspection of the geometry of $\mathbf{1 C H}_{2} \mathrm{~S}$ makes evident that many interactions concur in the stabilization of the adduct. The same conclusion can be drawn computing the deformation map between the adduct and the sum of the isolated fragments, showing how the electronic density changes upon the formation of the adduct $\left(\Delta \rho_{\text {tot }}\right.$, Figure 1$)$. Indeed, one set of accumulation/depletion (blue/red coloured regions) lies on the $\mathrm{Cd}-\mathrm{S}$ axis, another set on the $\mathrm{Cl}$ $\mathrm{H}$ axis, suggesting that the metal is interacting with the Lewis base, but there is also a hydrogen bond (HB). Their decomposition would be desirable for a complete bond analysis.

Although it is not possible to decompose $E_{\text {elst }}$ in chemically meaningful contributions, the same is possible with $E_{\text {orb. }}$ As the latter is very stable with the computational details (Table 1), from now on the M06 functonal will be used, coherently with the literature. ${ }^{16}$ The decomposition of $\mathrm{E}_{\text {orb }}$ could be done, in principle, by taking advantage of the symmetry of the system, at least in the case that different contributions belong to different irreducible representations. ${ }^{32}$ Anyway, often this approach requires a modification of the system experimentally studied in order to achieve a perfect symmetry. Alternatively, the Natural Orbital for Chemical Valence (NOCV) analysis allows the decomposition of $\Delta \rho_{\text {tot }}$ and $\mathrm{E}_{\text {orb }}$ into chemically meaningful contributions $\left(\Delta \rho_{\mathrm{k}}\right.$ and $E_{k}$ ) without passing through the irreducible representations. The two methodologies have been compared for halogen bonding and, when both are applicable, give similar results. ${ }^{28}$ 


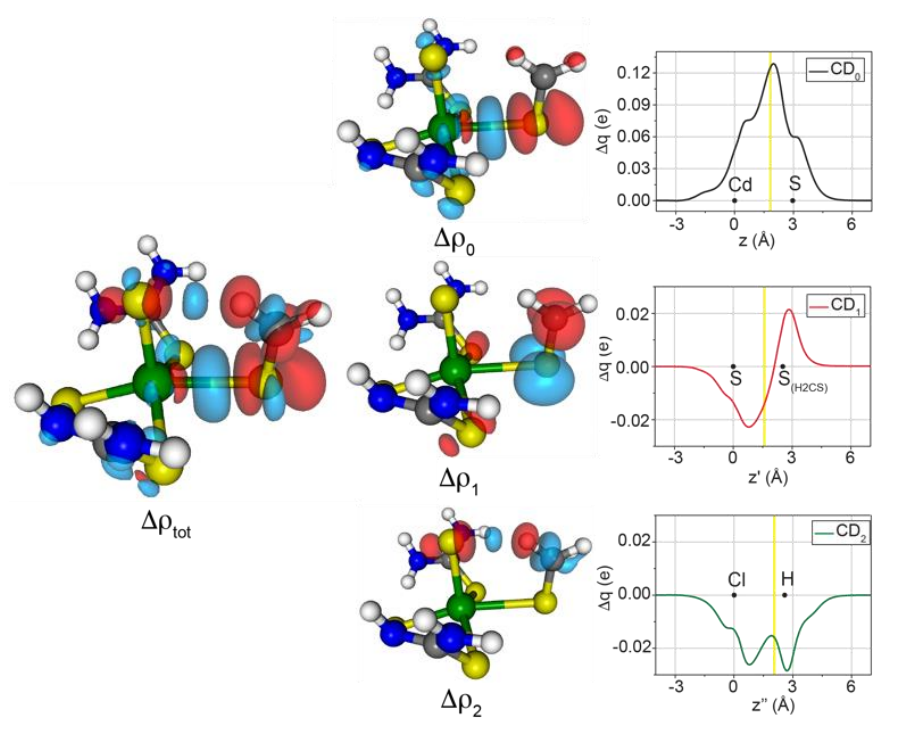

Figure 1. Isodensity surface plots (isodensity value 1 me a.u. ${ }^{-3}$ except for $\Delta \rho_{1}, 0.7$ me a.u. ${ }^{-3}$ ) for the deformation maps relative to $\Delta \rho_{\text {tot }}$ and $\Delta \rho_{\mathrm{k}}\left(\mathrm{k}=0,1\right.$ and 2) of the $[\mathbf{1}]^{\cdots}\left[\mathbf{C} \mathbf{H}_{2} \mathbf{S}\right]$ interaction. The charge flux is red $\rightarrow$ blue. Aside each $\Delta \rho_{\mathrm{k}}$ map, the corresponding Charge Displacement function is shown. Black dots indicate the position on the axis of the atomic nuclei. A yellow vertical band indicates the boundary between the fragments.

In the case of $\mathbf{1 C H}_{2} \mathrm{~S}$, the NOCV analysis is perfectly able to isolate the main components of the interaction (Figure 1):

- $\Delta \rho_{0}$ contains only the regions involved with the $\mathrm{S} \cdots \mathrm{Cd}$ interaction, with depletion regions around the sulfur, accumulation between the latter and cadmium and accumulation regions on the thioureas coordinated. The sulfur is donating electronic density to the metal and at the same time the electrons of the cadmium-thourea bonds are repelled by the presence of the LB. This term is the orbital equivalent of the "spodium bond" and accounts for $-7.2 \mathrm{kcal} / \mathrm{mol}$;

- $\Delta \rho_{1}$ describes a large polarization of the double bond of $\mathrm{CH}_{2} \mathrm{~S}$ upon the formation of the adduct: the interaction with a Lewis acid makes the electronic density move from $\mathrm{C}$ (depletion) to $\mathrm{S}$ (accumulation). Smaller details can be highlighted: the accumulation regions on the sulfur of the LB has a noticeable pointed shape toward the sulfur of the coordinated thiourea, whereas on the latter small depletion regions are present. This pattern indicates a weak S-S interaction (chalcogen bond, $\mathrm{ChB}) . \Delta \rho_{1}$ accounts for $-0.9 \mathrm{kcal} / \mathrm{mol}$;

- $\Delta \rho_{2}$ contains only the regions involved with the $\mathrm{Cl} \cdots \mathrm{H}$ interaction, with the typical pattern of a HB: depletion on chloride, accumulation between the latter and hydrogen and polarization pattern 
on $\mathrm{H}-\mathrm{C}$ bond. Noteworthy, the charge flux is on the opposite direction with respect to $\Delta \rho_{0} . \Delta \rho_{2}$ accounts for $-1.7 \mathrm{kcal} / \mathrm{mol}$;

- $\Delta \rho_{\mathrm{k}}$, with $\mathrm{k}>2$, contains only diffuse polarization regions that cannot be related to any specific and relevant bond components (Supporting Information). The sum of all these contributions accounts for the remaining $-2.0 \mathrm{kcal} / \mathrm{mol}$, with each contribution being smaller than $0.5 \mathrm{kcal} / \mathrm{mol}$. $\Delta \rho_{\mathrm{k}}$ can be separately integrated by the Charge Displacement analysis (CD) to have quantitative information about the electron density involved in each single contribution $(\Delta \mathrm{q}$, in millielectrons, me). Each interaction has been integrated along its axis (Cd-S for $\Delta \rho_{0}$, the bisector of the SSS angle for $\Delta \rho_{1}$ and $\mathrm{Cl}-\mathrm{H}$ for $\Delta \rho_{2}$ ) to give 3 separate $\mathrm{CD}$ functions. $\mathrm{CD}_{0}$ is found to be positive at any position, suggesting a net $C d \leftarrow S$ charge transfer (Figure 1). The value of $\Delta q$ at the isoboundary, $\mathrm{CT}_{0}\left(\mathrm{CT}_{\mathrm{spB}}\right)$ is $125 \mathrm{me}$ (Table 2). $\mathrm{CD}_{1}$ has a different behaviour as it is negative at first (charge transfer from 1 to $\mathrm{CH}_{2} \mathrm{~S}$ ) and then it changes sign because of the double bond polarization. At the isoboundary position, $\mathrm{CT}_{1}\left(\mathrm{CT}_{\mathrm{ChB}}\right)$ is equal to $-11 \mathrm{me}$. The latter is the sum of the projections of each single $\mathrm{S} \rightarrow \mathrm{S}$ CT on the chosen axis. Considering that the SSS angle is $86.7^{\circ}$, each $\mathrm{S} \rightarrow \mathrm{S}$ charge transfer can be estimated as $-7.6 \mathrm{me}$. The large polarization of the double bond interferes with this estimation, likely underestimating it. The $\mathrm{CD}$ relative to the $\mathrm{HB}$ is negative, as the direction of the flux is $\mathrm{Cl} \rightarrow \mathrm{H}$, but there is no change of sign, as also the polarization is toward the same direction. $\mathrm{CT}_{2}\left(\mathrm{CT}_{\mathrm{HB}}\right)$ is -18 me.

Table 2. Orbital energies (in $\mathrm{kcal} / \mathrm{mol}$ ) and CT values (in me) relative to the different bond components for the adducts between complexes 1-5 and $\mathrm{CH}_{3} \mathrm{CN}, \mathrm{CO}, \mathrm{CH}_{2} \mathrm{O}, \mathrm{CH}_{2} \mathrm{~S}$. 


\begin{tabular}{ccccc}
\hline Adduct & $\mathrm{E}_{\mathrm{orb}}$ & $\mathrm{E}_{\mathrm{SpB}}\left(\mathrm{CT}_{\mathrm{SpB}}\right)$ & $\mathrm{E}_{\mathrm{HB}}\left(\mathrm{CT}_{\mathrm{HB}}\right)$ & $\mathrm{E}_{\mathrm{ChB}}\left(\mathrm{CT}_{\mathrm{ChB}}\right)$ \\
\hline $\mathbf{1 C H} \mathbf{C N}$ & -6.2 & $-2.5(42)$ & $-1.4(-17)$ & $-0.3(5)$ \\
$\mathbf{1 C O}$ & -2.8 & $-0.7(15)$ & - & $-0.3(-2)$ \\
$\mathbf{1} \mathbf{C H}_{2} \mathbf{O}$ & -8.2 & $-4.5(65)$ & $-1.5(-17)$ & $-0.5(1)$ \\
$\mathbf{1 C H} \mathbf{C}$ & -11.8 & $-7.2(125)$ & $-1.7(-18)$ & $-0.9(-11)$ \\
$\mathbf{2 C O}$ & -2.4 & $-0.6(18)$ & $-1.0(-16)^{\mathrm{a}}$ & $-0.5(-6)$ \\
$\mathbf{3 C H} \mathbf{C N}$ & -3.8 & $-0.2(1)$ & $-1.5(-31)$ & $-0.6(8)$ \\
$\mathbf{3 C O}$ & -1.5 & $-0.3(9)$ & - & $-0.7(-3)$ \\
$\mathbf{3 C H _ { 2 } \mathbf { O }}$ & -3.0 & - & $-1.2(-27)$ & $-0.7(11)$ \\
$\mathbf{3 C H} \mathbf{C}$ & -3.6 & - & $-1.2(-12)$ & $-1.2(-1)$ \\
$\mathbf{4 C H _ { 2 } \mathbf { O }}$ & -4.5 & $-1.9(31)$ & $-1.2(-14)$ & - \\
$\mathbf{5} \mathbf{C H}_{3} \mathbf{C N}$ & -4.8 & $-1.2(18)$ & $-1.8(-24)$ & $-0.2(5)$ \\
$\mathbf{5} \mathbf{C O}$ & -2.1 & $-0.5(16)$ & $-0.1(-2)^{\mathrm{a}}$ & $-0.2(-3)$ \\
$\mathbf{5} \mathbf{C H}_{2} \mathbf{O}$ & -4.6 & $-1.9(27)$ & $-1.4(-15)$ & $-0.2(1)$ \\
$\mathbf{5} \mathbf{C H}_{2} \mathbf{S}$ & -6.1 & $-2.8(54)$ & $-1.7(-19)$ & $-0.4(-3)$ \\
\hline
\end{tabular}

${ }^{\mathrm{a}}$ Halogen $\rightarrow \mathrm{CO}$ transfer

Other [(thiourea $\left.)_{2} \mathbf{M X}_{2}\right]$ model systems. Also in the other $\mathrm{Cd}$ model systems the adducts are held together by more than one interactions. EDA data show that $\mathrm{E}_{\text {orb }}$ varies significantly as a function of the Lewis base and this is reflected also in its composition in the NOCV analysis. For example, replacing $\mathrm{CH}_{2} \mathrm{~S}$ with $\mathrm{CO}$ in 1 lowers the total interaction energy by over $6 \mathrm{kcal} / \mathrm{mol}$ $\left(E_{\text {int }}=-4.4 \mathrm{kcal} / \mathrm{mol}\right)$, with an $E_{\text {orb }}$ of only $-2.8 \mathrm{kcal} / \mathrm{mol}$. This clearly corresponds to the lack of HB but, more importantly, to a much weaker SpB contribution (Table 2). Obviously, the two things are not mutually independent, as the presence of an interaction can make the others stronger. The other donors investigated in combination with $\mathbf{1}$ fall in between these two extremes, in the order $\mathrm{E}_{\mathrm{SpB}} \mathrm{CH}_{2} \mathrm{~S}>\mathrm{CH}_{2} \mathrm{O}>\mathrm{CH}_{3} \mathrm{CN}>\mathrm{CO}$, with a clear correlation between $\mathrm{E}_{\text {int }}, \mathrm{E}_{\text {orb }}$ and $\mathrm{E}_{\mathrm{SpB}}$.

Interestingly enough, when chlorides are replaced by iodides in the $\mathrm{CO}$ adduct (2CO), a small $\mathrm{I} \rightarrow \mathrm{CO}$ contribution emerges, similar to what happens with coordinated triple bonds (see Supporting Information). ${ }^{33,34}$ This contribution is larger, in energy, than SpB and S-S CT (Table 2). 
Using a stronger Lewis bases as ammonia, the bond becomes coordinative (length $2.4 \AA$ ) and the $\mathrm{Cd}-\mathrm{N}$ bond possesses more than one component, as expected from the Dewar-Chatt-Duncanson model. In fact, applying the NOCV-CD analysis on $\mathbf{1} \mathbf{N H}_{3} \Delta \rho_{0}$ describes the $\mathrm{N} \rightarrow \mathrm{Cd} \sigma$ donation $\left(\mathrm{CT}_{0}=157 \mathrm{me}, \mathrm{E}_{0}=-13.5 \mathrm{kcal} / \mathrm{mol}\right), \Delta \rho_{1}$ and $\Delta \rho_{2}$ two different $\mathrm{Cd} \rightarrow \mathrm{N}$ small yet noticeable $\pi$ back-donation components $\left(\mathrm{CT}_{1}=-5 \mathrm{me}, \mathrm{CT}_{2}=-11 \mathrm{me}, \mathrm{E}_{1}=\mathrm{E}_{2}=-0.6 \mathrm{kcal} / \mathrm{mol}\right.$, Figure 2$)$.

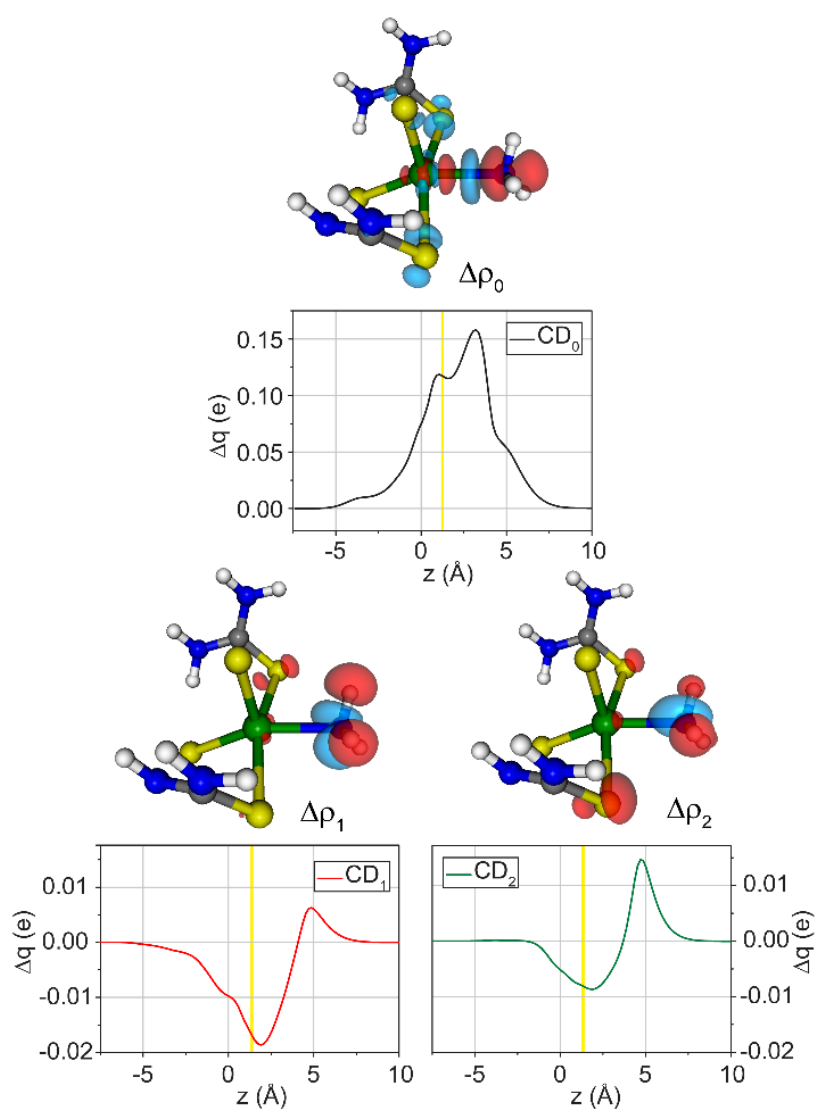

Figure 2. Isodensity surfaces (isodensity value 2 me a.u. ${ }^{-3}$ for $\Delta \rho_{0}, 0.5$ me a.u. ${ }^{-3}$ for $\Delta \rho_{1}$ and $\Delta \rho_{2}$ ) for the deformation maps relative to $\Delta \rho_{\mathrm{k}}(\mathrm{k}=1$ and 2) of the $\mathbf{1 N H} 3$ adduct. The charge flux is red $\rightarrow$ blue. Below each $\Delta \rho_{\mathrm{k}}$ map, the corresponding Charge Displacement function is shown. Black dots indicate the position on the axis of the atomic nuclei. A yellow vertical band indicates the boundary between the fragments.

The total EDA results (performed with $\mathrm{ADF}$ ) about the $\mathrm{Cd}-\mathrm{N}$ interaction are as follows: $\mathrm{E}_{\mathrm{int}}, \mathrm{E}_{\mathrm{orb}}$, $E_{\text {elst }}, E_{\text {Pauli }}$ and $E_{\text {disp }}$ are $-16.3,-18.2,-52.3,59.0$ and $-4.9 \mathrm{kcal} / \mathrm{mol}$, respectively. The strength of the interaction is about double than in the case of $1 \mathbf{C H}_{2} \mathrm{~S}$, but the ratio between $E_{\text {orb }}$ and the sum 
of all the attractive terms is $24 \%$, whereas it is $26 \%$ for $\mathbf{1 C H} 2 \mathbf{S}$. Just for comparison, for the Cdthiourea coordinative bond in the isolated $\mathbf{1 C H}_{2} \mathbf{S}$, this percentage is $32 \%\left(\mathrm{E}_{\mathrm{int}}=32.6 \mathrm{kcal} / \mathrm{mol}\right)$. The absence of the $\pi$ back-donation component supports that "spodium bond" is not coordinative, but the percentage of $E_{\text {orb}}$, being the same for coordinative and spodium bonds, suggests that the term "non covalent interaction" is reductive.

Passing from $\mathrm{Cd}$ to $\mathrm{Zn}$, the values of $\mathrm{E}_{\text {int }}$ are smaller than before (Table 3 ) and the orbital contribution of the $\mathrm{SpB}$ becomes almost negligible in the whole series, both in terms of energy (maximum -0.3 kcal/mol, Table 2) and electrons involved (0-9 me), reasonably owing to the lower polarizability of $\mathrm{Zn}$. From the orbital point of view, the zinc adducts are essentially held together by $\mathrm{HB}$, with a small contribution from $\mathrm{ChB}$ (Figure 3 and Table 2). For example, for the $\mathbf{3 C H}_{2} \mathbf{C S}$ adduct, the interaction energy is $-6.9 \mathrm{kcal} / \mathrm{mol}$, of which -3.6 is the orbital term and $2.5 \mathrm{kcal} / \mathrm{mol}$ is the steric term. The orbital term is decomposed mainly in $\Delta \rho_{0}$ (ChB component, $-1.2 \mathrm{kcal} / \mathrm{mol},-1 \mathrm{me}$ ), $\Delta \rho_{1}$ (HB component, $-1.2 \mathrm{kcal} / \mathrm{mol}, 12 \mathrm{me}$ ) and $\Delta \rho_{2}$ (double bond polarization, $-0.3 \mathrm{kcal} / \mathrm{mol}$ ). All of the other contributions are energetically negligible and do not show any sign of orbital $\mathrm{SpB}$.

Anyway, $\mathrm{E}_{\text {st }}$ values are slightly negative, indication that the electrostatic term is comparable to the Pauli repulsion term, confirming the importance of electrostatics: the ratio $\mathrm{E}_{\text {orb }} / \mathrm{E}_{\text {int }}$ is always smaller for zinc adducts than for the corresponding cadmium counterparts: indeed, such a ratio is 0.66 for $\mathbf{1 C H}_{3} \mathbf{C N}$ and 0.50 for $\mathbf{3 C H}_{3} \mathbf{C N}$. This indicates that for zinc adducts the global interaction is less covalent than for cadmium adducts, and it is a first indication that the spatial proximity is not enough to induce an orbital $\mathrm{SpB}$. This does not exclude that there could be a contribution of the polarized metal in the electrostatic term. 

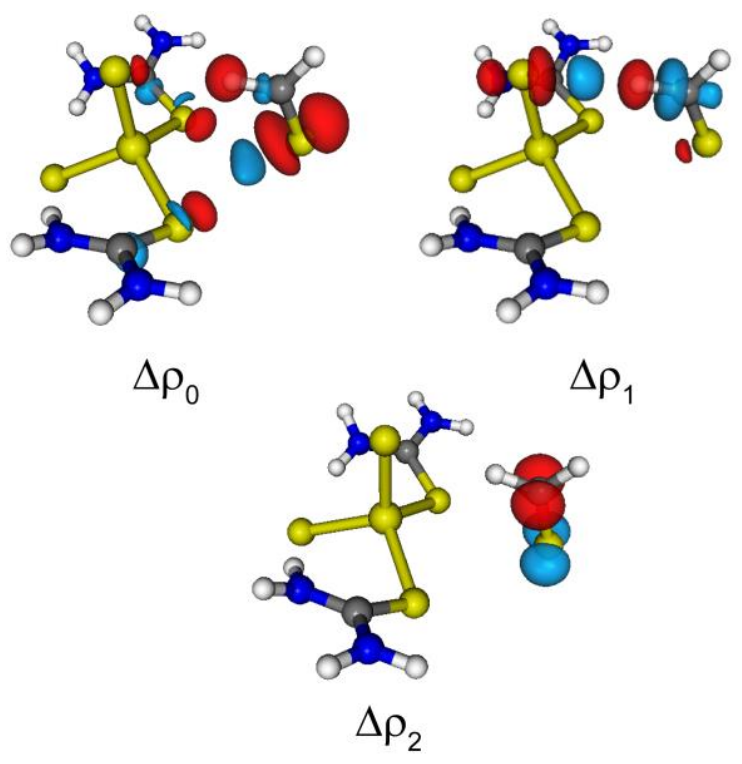

Figure 3. Isodensity surfaces (isodensity $0.5 \mathrm{me} \mathrm{a.u.}^{-3}$ ) for the deformation maps relative to $\Delta \rho_{\mathrm{k}}(\mathrm{k}=0$ 2) of the $\mathbf{3 C H}_{2} \mathbf{C S}$ adduct. The charge flux is red $\rightarrow$ blue.

Anyway, if the chloride trans to the LB is swapped with a fluoride, the SpB returns to be relevant for $\mathrm{E}_{\text {orb }}\left(-1.9 \mathrm{kcal} / \mathrm{mol}\right.$ and 31 me for $\left.\mathbf{4 H}_{2} \mathbf{C O}\right)$.

$\mathrm{Hg}$ complexes have an intermediate behaviour between that of $\mathrm{Cd}$ and $\mathrm{Zn}$ ones, first of all in terms of $E_{\text {int }}$, but also in terms of orbital spodium bond contribution. For example, $\mathbf{5 C H} 2 \mathbf{S}$ shows an $\mathrm{E}_{\mathrm{SpB}}$ of $-2.8 \mathrm{kcal} / \mathrm{mol}$, corresponding to a charge transfer of $54 \mathrm{me}, 71 \mathrm{me}$ lower than that of $\mathbf{1 C H}_{2} \mathrm{~S}$ (Table 2). This fits with the findings by Frontera et al., which showed that van der Waalscorrected $\mathrm{Cd} \cdots \mathrm{LB}$ distances are generally shorter than $\mathrm{Hg}{ }^{\cdots} \mathrm{LB}$ ones and electrostatic potentials are more positive on $\mathrm{Cd}$ than on $\mathrm{Hg}$. This is likely due to the combination of the smaller atomic radius of $\mathrm{Hg}$ and the steric congestion around the metal, which do not allow an efficient approach by the LB. This is even more evident for the other donors in the series, where the SpB is not the dominant term and has a similar or lower energy contribution than HB contributions.

Table 3. EDA results (in $\mathrm{kcal} / \mathrm{mol}$ ) for the adducts between complexes $\mathbf{1 - 5}$ and $\mathrm{CH}_{3} \mathrm{CN}, \mathrm{CO}$, $\mathrm{CH}_{2} \mathrm{O}, \mathrm{CH}_{2} \mathrm{~S}$. 


\begin{tabular}{ccccc}
\hline Adduct & $\mathrm{E}_{\text {int }}$ & $\mathrm{E}_{\text {orb }}$ & $\mathrm{E}_{\text {st }}$ & $\mathrm{E}_{\text {disp }}$ \\
\hline $\mathbf{1 C H} \mathbf{C N}$ & -9.4 & -6.2 & -2.2 & -0.9 \\
$\mathbf{1 C O}$ & -4.4 & -2.8 & -1.2 & -0.4 \\
$\mathbf{1} \mathbf{C H}_{2} \mathbf{O}$ & -9.0 & -8.2 & -0.1 & -0.7 \\
$\mathbf{1} \mathbf{C H}_{2} \mathbf{S}$ & -10.5 & -11.8 & 2.2 & -0.9 \\
$\mathbf{1} \mathbf{N H}_{3}$ & -21.9 & -16.9 & -4.3 & -0.7 \\
$\mathbf{2 C O}$ & -3.4 & -2.4 & -0.4 & -0.6 \\
$\mathbf{3 C H} \mathbf{C N}$ & -7.6 & -3.8 & -2.8 & -1.1 \\
$\mathbf{3 C O}$ & -3.2 & -1.5 & -1.2 & -0.5 \\
$\mathbf{3 C H} \mathbf{O}$ & -6.1 & -3.0 & -2.5 & -0.7 \\
$\mathbf{3 C H} \mathbf{S}$ & -6.9 & -3.6 & -2.5 & -0.8 \\
$\mathbf{4} \mathbf{C H}_{2} \mathbf{O}$ & -7.5 & -4.5 & -2.4 & -0.6 \\
$\mathbf{5} \mathbf{C H}_{3} \mathbf{C N}$ & -8.3 & -4.8 & -2.4 & -1.1 \\
$\mathbf{5} \mathbf{C O}$ & -3.6 & -2.1 & -0.9 & -0.6 \\
$\mathbf{5} \mathbf{C H}_{2} \mathbf{O}$ & -6.9 & -4.6 & -1.6 & -0.7 \\
$\mathbf{5} \mathbf{C H}_{2} \mathbf{S}$ & -8.2 & -6.1 & -1.2 & -0.9 \\
\hline
\end{tabular}

Also for mercury, $\mathrm{E}_{\text {st }}$ is slightly negative and generally the ratio $\mathrm{E}_{\mathrm{orb}} / \mathrm{E}_{\text {int }}$ is intermediate between those of cadmium and zinc adducts.

Real systems. From our analysis on model systems, it clearly appears that the relative extent of the SpB orbital contribution strongly depends on the system investigated: not only the nature of the metal, but also its degree of polarization. Also, while generally larger SpB contributions lead to shorter M $\cdots$ LB distances, there is no obvious correlation between donor-acceptor distance and interaction energy in none of the compound series. This happens because when more interactions are active at the same time, the final geometry depends on the combinations of all of them. ${ }^{28}$ For this reason, it is of interest to extend NOCV-CD to experimentally characterised group 12 complexes showing short, but not coordinative $\mathrm{X}-\mathrm{M} \cdots \mathrm{LB}$ arrangements. This allows to probe whether they arise from a net $\mathrm{SpB}$ charge transfer and what is the role of the other intermolecular interactions in determining such arrangements. 
$\mathrm{Zn}$

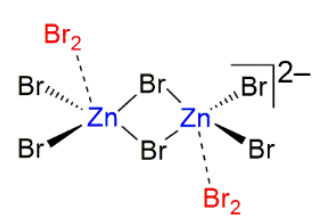

ASEZIJ

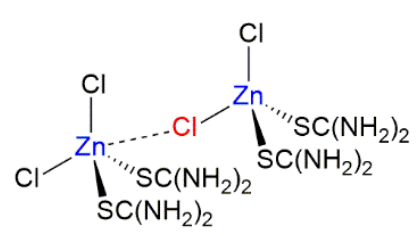

VARCEY

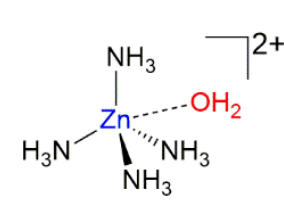

YAGGET

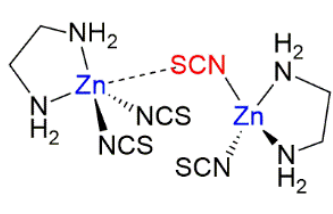

GOVLAE

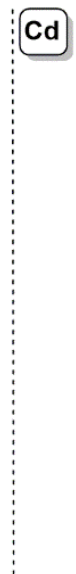

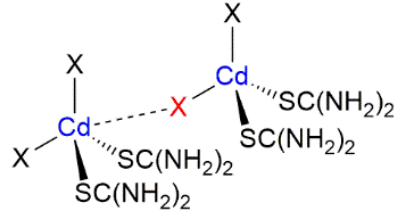

CTURCD ( $\mathrm{X}=\mathrm{Cl}$ ), PEKSUT ( $\mathrm{X}=\mathrm{Br}$ )

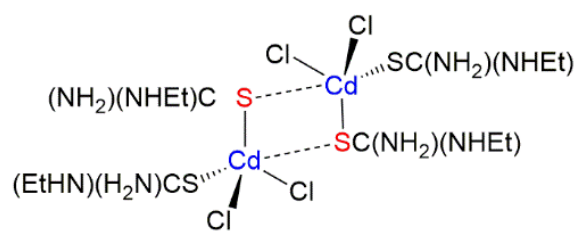

HUWYON

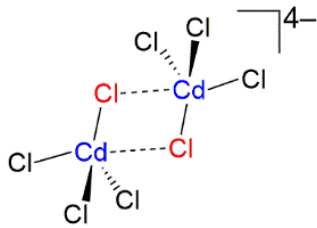

отоFOU

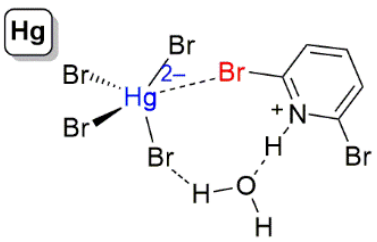

DUKTAF

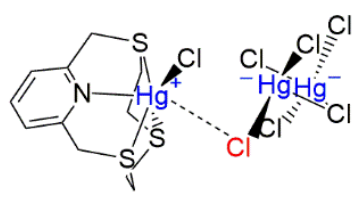

KUSMAM

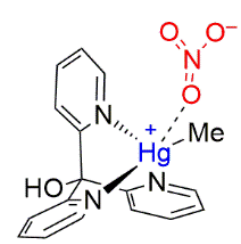

BEJGOM

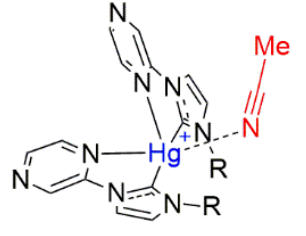

DEZGEV

Scheme 2. Experimentally characterised structures selected for NOCV-CD analysis with their respective $\mathrm{CCDC}$ code; dashed lines represent putative $\mathrm{SpB}$ interactions.

By analysing the database of structures with reduced $\mathrm{M} \cdots \mathrm{LB}$ distances compatible with $\mathrm{SpB},{ }^{18}$ we have selected exemplificative adducts for each metal containing different ligands, charges and donor types (Scheme 2). We deliberately chose fragments with a large span of interactions energies, ranging from very positive (OTOFOU) to very negative (DUKTAF) values of $E_{\text {int, }}$, to check how the latter impacts on $\mathrm{E}_{\text {orb }}$ and its decomposition into contributions.

EDA results (Table 4) clearly show that all the structures have a favourable orbital contribution to $E_{\text {int }}\left(E_{\text {orb }}<0\right)$, even when the two fragments would repel each other when taken out of the crystal lattice, as in OTOFOU, where two $\left[\mathrm{CdCl}_{4}\right]^{2-}$ anions are close each other. As only the orbital term is important in the NOCV-CD analysis, the intrinsic instability of the isolated adduct is not an issue, here. And, indeed, the decomposition of $E_{\text {orb }}$ for such structures by NOCV (Table 4) offers interesting details about the impact of the different intermolecular interactions.

Starting with zinc systems, two different adducts can be isolated from the ASEZIJ lattice (-a and -b in Table 4), the former of which has an $E_{\text {int }}$ much smaller than the latter. In both cases, the bromine atom, although it is spatially close to the zinc and laying more or less on the prolongation of the $\mathrm{Br}-\mathrm{Zn}$ bond $\left(\mathrm{Br}-\mathrm{Zn} \cdots \mathrm{Br}\right.$ angles $=163.9$ and $143.9^{\circ}$, respectively $)$, does not show any $\mathrm{SpB}$ orbital contribution. The 
only orbital interaction is a halogen bond (XB) between the $\sigma$ hole on the $\mathrm{Br}_{2}$ moiety and the lone pairs of the bromine atoms coordinated to the zinc. As before, it cannot be excluded that the presence of the metal could be important in the electrostatic term in determining the adduct geometry.

Table 4. EDA results (in $\mathrm{kcal} / \mathrm{mol}$ ) and $\mathrm{CT}$ values (in me) relative to the different bond components for experimental solid-state dimers from CCDC.

\begin{tabular}{|c|c|c|c|c|c|c|c|c|c|}
\hline Adduct & $\mathrm{E}_{\text {int }}$ & $E_{\text {orb }}$ & $\mathrm{E}_{\mathrm{st}}$ & $\mathrm{E}_{\mathrm{disp}}$ & $\mathrm{E}_{\mathrm{SpB}}\left(\mathrm{CT}_{\mathrm{SpB}}\right)$ & $\mathrm{E}_{\mathrm{HB}}\left(\mathrm{CT}_{\mathrm{HB}}\right)$ & $\mathrm{E}_{\mathrm{ChB}}\left(\mathrm{CT}_{\mathrm{ChB}}\right)$ & $\mathrm{E}_{\mathrm{XB}}\left(\mathrm{CT}_{\mathrm{XB}}\right)$ & ref \\
\hline \multicolumn{10}{|c|}{$\mathrm{M}=\mathrm{Zn}$} \\
\hline ASEZIJ-a & -8.8 & -6.1 & -2.3 & -0.4 & - & - & - & $-4.5(-77)$ & 35 \\
\hline ASEZIJ-b & -15.2 & -14.8 & 0.0 & -0.5 & - & - & - & $-12.9(-136)$ & 35 \\
\hline YAGGET & -17.4 & -3.2 & -13.5 & -0.7 & $-1.8(25)$ & - & - & - & 36 \\
\hline GOVLAE & -21.6 & -6.6 & -12.8 & -2.2 & -1.1 (a) & $-2.4(-45)$ & - & - & 37 \\
\hline VARCEY & 1.1 & -3.8 & 6.9 & -2.0 & - & $-1.3(24)$ & - & - & 38 \\
\hline \multicolumn{10}{|c|}{$\mathrm{M}=\mathrm{Cd}$} \\
\hline PEKSUT & -1.6 & -6.5 & 6.9 & -2.0 & $-2.7(56) b$ & - & $-1.1(1)$ & - & 39 \\
\hline CTURCD & -2.9 & -6.1 & 5.3 & -2.1 & $-2.3(46) b$ & - & - & - & 40 \\
\hline OTOFOU & 206.5 & -14.1 & 221.2 & -0.7 & $-3.1(\mathrm{c})$ & - & - & - & 41 \\
\hline \multirow[t]{2}{*}{ HUWYON } & -25.6 & -10.4 & -13.0 & -2.2 & - & $-2.5(\mathrm{c})$ & - & - & 42 \\
\hline & & & & & & \multicolumn{4}{|l|}{$-1.6(c)$} \\
\hline & & & & & $\mathrm{M}=\mathrm{Hg}$ & & & & \\
\hline DUKTAF & -133.4 & -19.7 & -112.5 & -1.1 & - & $-3.2(-52)$ & - & $-5.7(-64)$ & 43 \\
\hline \multirow[t]{2}{*}{ KUSMAM } & -117.5 & -23.5 & -91.7 & -2.4 & $-5.4(-79)$ & - & $-3.7(-45)$ & - & 44 \\
\hline & & & & & $-2.4(4)$ & & & & \\
\hline BEJGOM & -76.3 & -14.2 & -60.7 & -1.5 & $-5.2(58)$ & $-1.3(-33)$ & - & - & 45 \\
\hline DEZGEV & -17.7 & -6.2 & -9.5 & -2.0 & $-2.8(33)$ & - & - & - & 46 \\
\hline
\end{tabular}

a: mixed wth HB, see ESI; b: mixed with $\mathrm{ChB}$, see ESI; c: integration unfeasible due to the symmetry of the adduct.

On the contrary, in the dimer extracted from YAGGET, the oxygen of water prefers to establish an orbital $\mathrm{SpB}$ with zinc rather than a selective $\mathrm{HB}$ with the ammonia protons (Figure 4a). In this way, it can electrostatically interact with all the amino protons. The integration of the corresponding function, $\Delta \rho_{0}$, leads to a $\mathrm{CT}_{0}$ of $25 \mathrm{me}(-1.8 \mathrm{kcal} / \mathrm{mol})$, which is the sum of the water polarization under the electrostatic effect of the amino protons and the orbital $\mathrm{SpB}$, the presence of which is confirmed by the presence of a second maximum in the integrated function (Figure $4 a$ ). 
a)
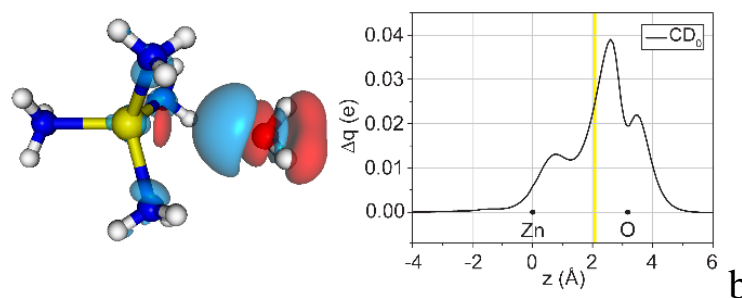

b)
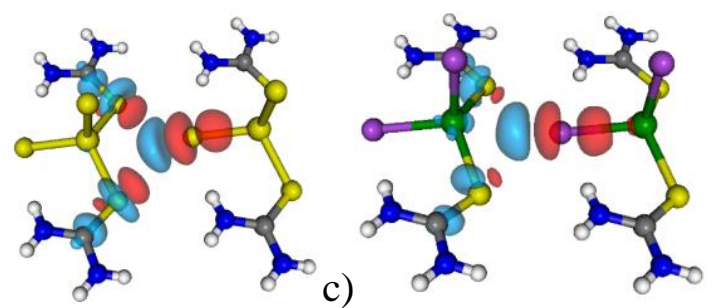

)

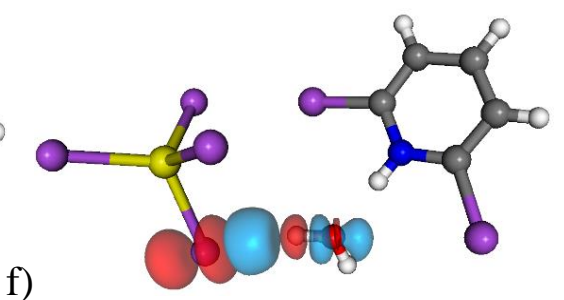

d)

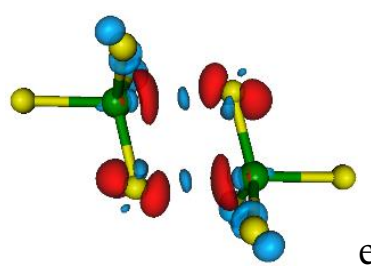

e)

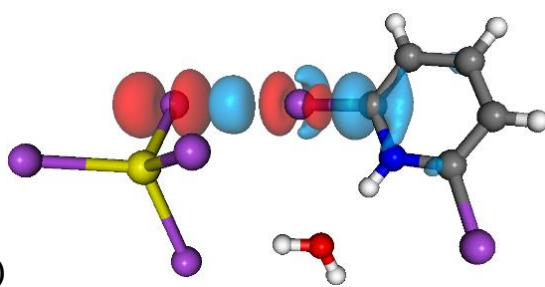

f)

Figure 4. Isodensity surface plots for the deformation maps relative to a) $\Delta \rho_{0}$ of the YAGGET adduct (isodensity value 0.5 me a.u. ${ }^{-3}$ ) and, aside, the corresponding Charge Displacement function; b) $\Delta \rho_{0}$ of the VARCEY adduct (isodensity value 0.3 me a.u. ${ }^{-3}$ ); c) $\Delta \rho_{0}$ of the PEKSUT adduct (isodensity value 0.6 me a.u. ${ }^{-3}$ ); d) $\Delta \rho_{0}$ of the OTOFOU adduct (isodensity value 0.5 me a.u. ${ }^{-3}$ ); e) $\Delta \rho_{1}$ of the DUKTAF adduct (isodensity value 1.0 me a.u. ${ }^{-3}$ ); f) $\Delta \rho_{2}$ of the DUKTAF adduct (isodensity value 0.8 me a.u. ${ }^{-3}$ ). The charge flux is red $\rightarrow$ blue.

In the case of GOVLAE, the adduct is mainly held together by HBs between the amino protons and the sulfur atoms, but tiny polarization regions on the metal in $\Delta \rho_{1}$ does not allow to completely exclude the presence of a small $\mathrm{SpB}$.

In VARCEY (Figure 4b), no SpB can be found in the NOCV terms. In fact, it is true that an accumulation region is present between the chlorine and the zinc, but there is no depletion/accumulation pattern on the metal. On the other hand, such a pattern is on the coordinated thioureas, suggesting that this term refers only to the $\mathrm{ChB}$ between the lone pairs of chloride and the $\sigma$-holes of the sulfur atoms and, despite the spatial proximity of chlorine and zinc, no actual $\mathrm{SpB}$ is present.

The comparison with PEKSUT and CTURCD, which are very similar to VARCEY but with cadmium instead of zinc (and bromine instead of chlorine for CTURCD), reveals how SpB is sensitive to the details of the structure. In fact, in PEKSUT and CTURCD, accumulation regions are clearly visible on the metal $\left(\Delta \rho_{0}\right.$, Figure $4 \mathrm{c}$ and Supporting Information) and on the thiourea ligands, indication that $\mathrm{SpB}$ and $\mathrm{ChB}$ in this case are not perfectly separated. Noteworthy, also $\Delta \rho_{1}$ refers the ChB (see Supporting Information).

HUWYON is held together only by HBs, with no involvement of the metal (see Supporting Information), whereas about OTOFOU we already mentioned that it has a relevant orbital contribution, even if it is a 
stable adduct only if placed in its crystal lattice. In this case, the analysis of $E_{\text {Pauli }}$ and $E_{\text {elst }}$ is not very informative, while the analysis of $\mathrm{E}_{\text {orb }}$ is still greatly useful. Both $\Delta \rho_{0}$ and $\Delta \rho_{1}$ contains orbital $\mathrm{SpB}$ contributions associated with large polarization effects (Figure 4d), which are unavoidable when two anions are close each other. Unfortunately, the integration of the $\Delta \rho$ functions is not informative, as the adduct is so symmetrical that any flux from one fragment to the other is counterbalanced by a similar one with opposite sign, making the sum null.

Finally, for mercury adducts, the fragment isolated from the DUKTAF lattice contains three moieties and has been separated into two fragments, $\left[\mathrm{HgBr}_{4}\right]^{2-}$ and $\left[\left(\mathrm{H}_{2} \mathrm{O}\right)(\mathrm{BrPyH})\right]^{+}$. The fragmentation could have been $\left[\left(\mathrm{HgBr}_{4}\right)\left(\mathrm{H}_{2} \mathrm{O}\right)\right]^{2-}$ and $\left[\mathrm{BrPyH}^{+}\right.$with no substantial differences. Despite the spatial proximity of the bromine to the mercury, the only intermolecular interactions here are a XB between the coordinated bromine (LB) and the bromine on the pyridinium (LA) and a HB between another coordinated bromine and the water (Figure $4 \mathrm{e}$ and $\mathrm{f}$ ). The very large value of $\mathrm{E}_{\text {int }}$ obviously depends on the electrostatic cation/anion attraction, but this contribution is mainly in $\mathrm{E}_{\text {st }}$ and does not affect much $\mathrm{E}_{\text {orb. }}$.

KUSMAM is interesting, too, because the adduct contains two different mercury atoms, one belonging to the anion and the second to the cation, and both of them are bound to chlorine ligands. The NOCV$\mathrm{CD}$ analysis reveals not only that a chlorine on the anion establishes a $\mathrm{SpB}$ with the mercury on the cation (79 me, see Table 4), but also, less obvious, viceversa: the chlorine on the cation donates a very small amount of charge ( $5 \mathrm{me}$ ) to the mercury on the anion (see Supporting Information).

In BEJGOM the nitrate anion establishes either a $\mathrm{SpB}$ with the mercury (58 me), but also a $\mathrm{HB}$ with a hydrogen of the complex (-33 me), whereas in DEZGEV the nitrogen of the acetonitrile shows a $\mathrm{N} \rightarrow$ Hg charge transfer of 33 me (see Supporting Information).

It is interesting to note that for each metal, both examples with and without an orbital SpB can be found and quantified, making difficult to give a general rule for the occurrence of SpB. Of course, a polarized metal is needed, but this is not uncommon: in many cases the metal is bound to electronegative atoms and therefore a $\sigma$-hole can likely be present. For lighter and less polarizable metals, as zinc, the polarization, and hence $\mathrm{SpB}$, is more difficult to achieve, but if electrostatics keep the LB in the right position, as in YAGGET, the SpB can be induced. Secondly, the LB should be not too strong to coordinate and not too weak to not interact. Anyway, a pure $\mathrm{SpB}$ is difficult to obtain, as the ancillary ligands around the metal very likely establish other weak interactions with the LB, in some cases favouring the occurrence of $\mathrm{SpB}$, as the $\mathrm{HB}$ in the model systems.

From the methodological point of view, the separation of the contributions is often perfect, with some exceptions. In addition, it should be highlighted that the NOCV-CD analysis is quite fast (three single 
point calculations, generally taking from 0.5 to $10 \mathrm{~h}$ depending on the size of the system), robust with respect to the choice of the computational details and greatly informative.

\section{Conclusions}

In summary, we have shown here that the NOCV-CD analysis allows the disentanglement of the complex network of weak interactions that drives the non-coordinative attraction between group 12 complexes and Lewis bases.

By assessing the orbital contribution to the interaction energy, we could characterize each component separately and observe that a net LB $\rightarrow \mathrm{M}$ charge transfer, compatible with the establishment of the socalled Spodium Bond (SpB), can occur. The extent of such contribution is strongly affected by the metal,

ligands and bases involved and generally, when the same ligand set is investigated, it seems to be more important for $\mathrm{Cd}$ complexes than for $\mathrm{Hg}$ and $\mathrm{Zn}$.

The application of this method to "real-life" structures revealed that there is no direct correlation between short $\mathrm{M} \cdots \mathrm{LB}$ distances and $\mathrm{LB} \rightarrow \mathrm{M}$ charge transfer, as other intermolecular forces such as hydrogen, chalcogen or halogen bond can intervene in determining the structural features of that particular molecular network. Therefore, while it can be used as a screening parameter while looking for potential SpB interactions, a M $\cdots$ LB distance shorter than the sum of the van der Waals radii does not guarantee that a net SpB will be present, so each structure needs to be evaluated individually. NOCV-CD, at this point, can be used to quickly visualize whether the bond has an orbital contribution or not.

\section{Acknowledgements}

This work was supported by the University of Pisa (PRA_2018_36 grant). LR is thankful to the University of East Anglia for support. Dr. Leonardo Belpassi is acknowledged for the use of ADF.

\section{Conflicts of interest}

There are no conflicts to declare.

\section{Computational Details}

All the geometries were optimized with ORCA 4.1.0, ${ }^{47,48}$ using the M06 functional. Dispersion forces were taken into account by using the D3 correction with zero damping (Becke-Johnson damping is not available for M06). ${ }^{49}$ Relativistic effects were treated with the scalar zeroth-order regular approximation (ZORA). The basis set was ZORA-TZVP for all the atoms except for iodine, cadmium and tellurium, for 
which OLD-ZORA-TZVP was used, and mercury, for which SARC-ZORA-TZVP was used. Coulombfitting auxiliary basis sets SARC/J have been used. The grid was set to 5, the scf requirements were set to "very tight" and the number of radial points was set to 6 . No negative frequencies were found. Geometries taken form literature (ref. ${ }^{18}$ and CCDC) have not been re-optimized.

\section{Energy decomposition analysis (EDA). ${ }^{19}$}

The EDA has been performed with a large variety of functional/basis sets combinations, either using ORCA or ADF (development version r47686). The EDA allows the decomposition of the bond energy into physically meaningful contributions. The interaction energy $\left(\mathrm{E}_{\mathrm{int}}\right)$ is the difference of energy between the adduct and the unrelaxed fragments. It can be divided into contributions associated with the orbital, steric and dispersion interactions, as shown in eqn (1)

$$
\mathrm{E}_{\text {int }}=\mathrm{E}_{\mathrm{st}}+\mathrm{E}_{\mathrm{orb}}+\mathrm{E}_{\mathrm{disp}}
$$

$E_{\text {st }}$ is usually called the steric interaction energy and it is the sum of $E_{\text {elst }}$, the classical electrostatic interaction between the unperturbed charge distributions of the fragments $\left(\rho_{A}\right.$ and $\left.\rho_{B}\right)$ at their final positions in the adduct, and the Pauli repulsion (EPauli) that is the energy change associated with going from $\rho_{A}+\rho_{B}$ to the antisymmetrized and renormalized wave function. The decomposition of $E_{s t}$ is not possible with ORCA 4.1.0. E st $_{\text {st }}$ comprises the destabilizing interactions between the occupied orbitals and is responsible for any steric repulsion. $E_{\text {orb }}$ is the contribution arising from allowing the wave function to relax to the fully converged one, accounting for electron pair bonding, charge transfer and polarization, while $\mathrm{E}_{\mathrm{disp}}$ is the contribution of the dispersion forces. ADF2014 has been used to decompose $\Delta \mathrm{E}_{\text {Pauli }}$ and $\Delta E_{\text {elst. }}$

\section{Charge Displacement function analysis.}

The Charge Displacement function analysis is based on Eq. (2). $\Delta \rho(\mathrm{x}, \mathrm{y}, \mathrm{z})$ is the difference between the electron density of a complex and that of its non-interacting fragments placed in the same position as they occupy in the complex. In the present case, the fragmentation depends on the interaction under examination and are generally indicated in each case. The function $\Delta q\left(z^{\prime}\right)$ defines, at each point along a chosen axis, the amount of electron charge that, upon formation of the bond between the fragments, moves across a plane perpendicular to the axis through the point $z$ '. A positive (negative) value corresponds to electrons flowing in the direction of decreasing (increasing) z. Charge accumulates where the slope of $\Delta \mathrm{q}$ is positive and decreases where it is negative.

$$
\Delta q\left(z^{\prime}\right)=\int_{-\infty}^{+\infty} d x \int_{-\infty}^{+\infty} d y \int_{-\infty}^{z \prime} d z \Delta \rho(x, y, z)
$$


where $\Delta \rho(\mathrm{x}, \mathrm{y}, \mathrm{z})$ is the difference between the electron densities of a complex and the sum of that of its non-interacting fragments, frozen at the same geometry they assume in the complex.

We make use of the natural orbital for chemical valence theory (NOCV): ${ }^{23,50} \Delta \rho$ ' is built from the occupied orbitals of A and B, suitably orthogonalized to each other and renormalized (promolecule), using the "valence operator" (Eq. 3), ${ }^{51-53}$

$$
\widehat{V}=\sum_{i}\left(\left|\psi_{i}^{(A B)}\right\rangle\left\langle\psi_{i}^{(A B)}|-| \psi_{i}^{0}\right\rangle\left\langle\psi_{i}^{0}\right|\right)
$$

where $\psi_{\mathrm{i}}{ }^{0}$ is the set of the occupied Kohn-Sham orbitals of fragments A and B, mutually orthonormalized, and $\psi_{\mathrm{i}}^{(\mathrm{AB})}$ is the set of occupied orbitals of the adduct. The NOCVs can be grouped in pairs of complementary orbitals $\left(\varphi_{\mathrm{k}}, \varphi_{-\mathrm{k}}\right)$ corresponding to eigenvalues with same absolute value but opposite sign (Eq. 4).

$$
\widehat{V} \varphi_{ \pm k}= \pm v_{k} \varphi_{ \pm k}\left(v_{k}>0\right)
$$

where $k$ numbers the NOCV pairs $\left(k=0\right.$ for the largest value of $\left.\left|v_{\mathrm{k}}\right|\right)$. In this framework, $\Delta \rho$ ' can be defined as in Eq. 5.

$$
\Delta \rho^{\prime}=\sum_{k} v_{k}\left(\left|\varphi_{k}\right|^{2}-\left|\varphi_{-k}\right|^{2}\right)=\sum_{k} \Delta \rho^{\prime}{ }_{k}
$$

For each value of $k$, an energy contribution associated with the $k$-th NOCV pair is given. Now the different $\Delta \rho{ }^{\prime}{ }_{k}$ can be separately integrated using Eq. $2 .^{26,54}$

\section{References}

(1) Politzer, P.; Murray, J. S.; Clark, T. Halogen Bonding and Other $\sigma$-Hole Interactions: A Perspective. Physical Chemistry Chemical Physics. The Royal Society of Chemistry June 18, 2013, pp 11178-11189.

(2) Wang, H.; Bisoyi, H. K.; Urbas, A. M.; Bunning, T. J.; Li, Q. The Halogen Bond: An Emerging Supramolecular Tool in the Design of Functional Mesomorphic Materials. Chem. - A Eur. J. 2019, 25 (6), 1369-1378.

(3) Cavallo, G.; Metrangolo, P.; Milani, R.; Pilati, T.; Priimagi, A.; Resnati, G.; Terraneo, G. The Halogen Bond. Chem. Rev. 2016, 116 (4), 2478-2601.

(4) Desiraju, G. R.; Ho, P. S.; Kloo, L.; Legon, A. C.; Marquardt, R.; Metrangolo, P.; Politzer, P.; Resnati, G.; Rissanen, K. Definition of the Halogen Bond (IUPAC Recommendations 2013). Pure Appl. Chem. 2013, 85 (8), 1711-1713.

(5) Pascoe, D. J.; Ling, K. B.; Cockroft, S. L. The Origin of Chalcogen-Bonding Interactions. J. Am. Chem. Soc. 2017, 139 (42), 15160-15167. 
(6) Scilabra, P.; Terraneo, G.; Resnati, G. The Chalcogen Bond in Crystalline Solids: A World Parallel to Halogen Bond. Acc. Chem. Res. 2019, 52, 1313-1324.

(7) Garrett, G. E.; Gibson, G. L.; Straus, R. N.; Seferos, D. S.; Taylor, M. S. Chalcogen Bonding in Solution: Interactions of Benzotelluradiazoles with Anionic and Uncharged Lewis Bases. J. Am. Chem. Soc. 2015, 137 (12), 4126-4133.

(8) Aakeroy, C. B.; Bryce, D. L.; Desiraju, G. R.; Frontera, A.; Legon, A. C.; Nicotra, F.; Rissanen, K.; Scheiner, S.; Terraneo, G.; Metrangolo, P.; et al. Definition of the Chalcogen Bond (IUPAC Recommendations 2019). Pure Appl. Chem. 2019, 91 (11), 1889-1892.

(9) Scilabra, P.; Terraneo, G.; Resnati, G. Fluorinated Elements of Group 15 as Pnictogen Bond Donor Sites. Journal of Fluorine Chemistry. Elsevier B.V. November 1, 2017, pp 62-74.

(10) Bauzá, A.; Seth, S. K.; Frontera, A. Tetrel Bonding Interactions at Work: Impact on Tin and Lead Coordination Compounds. Coordination Chemistry Reviews. Elsevier B.V. April 1, 2019, pp 107-125.

(11) Bauzá, A.; Mooibroek, T. J.; Frontera, A. The Bright Future of Unconventional $\sigma / \pi$-Hole Interactions. ChemPhysChem. Wiley-VCH Verlag August 1, 2015, pp 2496-2517.

(12) Politzer, P.; Murray, J. S. Electrostatics and Polarization in $\sigma$ - and $\pi$-Hole Noncovalent Interactions: An Overview. ChemPhysChem. Wiley-VCH Verlag April 2, 2020, pp 579-588.

(13) Thomas, J. M.; Walker, N. R.; Cooke, S. A.; Gerry, M. C. L. Microwave Spectra and Structures of $\mathrm{KrAuF}, \mathrm{KrAgF}$, and $\mathrm{KrAgBr}$; 83Kr Nuclear Quadrupole Coupling and the Nature of Noble Gas-Noble Metal Halide Bonding. J. Am. Chem. Soc. 2004, 126 (4), 1235-1246.

(14) Evans, C. J.; Lesarri, A.; Gerry, M. C. L. Noble Gas-Metal Chemical Bonds. Microwave Spectra, Geometries, and Nuclear Quadrupole Coupling Constants of $\mathrm{Ar}-\mathrm{AuCl}$ and $\mathrm{Kr}-\mathrm{AuCl} . J$. Am. Chem. Soc. 2000, 122 (25), 6100-6105.

(15) Legon, A. C.; Walker, N. R. What's in a Name? "Coinage-Metal” Non-Covalent Bonds and Their Definition. Physical Chemistry Chemical Physics. Royal Society of Chemistry July 25, 2018, pp 19332-19338.

(16) Joy, J.; Jemmis, E. D. Contrasting Behavior of the Z Bonds in X-Z $\cdots Y$ Weak Interactions: Z= Main Group Elements Versus the Transition Metals. Inorg. Chem. 2017, 56 (3), 1132-1143.

(17) Alkorta, I.; Elguero, J.; Frontera, A. Not Only Hydrogen Bonds: Other Noncovalent Interactions. Crystals. MDPI AG March 6, 2020, p 180.

(18) Bauzá, A.; Alkorta, I.; Elguero, J.; Mooibroek, T. J.; Frontera, A. Spodium Bonds: Noncovalent Interactions Involving Group 12 of Elements. Angew. Chemie Int. Ed. 2020, anie.202007814. 
(19) Hopffgarten, M. von; Frenking, G. Energy Decomposition Analysis. Wiley Interdiscip. Rev. Comput. Mol. Sci. 2012, 2 (1), 43-62.

(20) Frenking, G.; Krapp, A. Unicorns in the World of Chemical Bonding Models. J. Comput. Chem. 2007, 28 (1), 15-24.

(21) Xia, T.; Li, D.; Cheng, L. Theoretical Analysis of the Spodium Bonds in HgCl2 $\cdots \mathrm{L}(\mathrm{L}=\mathrm{ClR}$, SR2, and PR3) Dimers. Chem. Phys. 2020, 539, 110978.

(22) Mitoraj, M. P.; Michalak, A.; Ziegler, T. A Combined Charge and Energy Decomposition Scheme for Bond Analysis. J. Chem. Theory Comput. 2009, 5 (4), 962-975.

(23) Radoń, M. On the Properties of Natural Orbitals for Chemical Valence. Theor. Chem. Acc. 2008, $120(4-6), 337-339$.

(24) Ciancaleoni, G.; Nunzi, F.; Belpassi, L. Charge Displacement Analysis-A Tool to Theoretically Characterize the Charge Transfer Contribution of Halogen Bonds. Molecules 2020, $25(2), 300$.

(25) Ciancaleoni, G. Lewis Base Activation of Lewis Acid: A Detailed Bond Analysis. ACS Omega 2018, 3 (11), 16292-16300.

(26) Bistoni, G.; Rampino, S.; Tarantelli, F.; Belpassi, L. Charge-Displacement Analysis via Natural Orbitals for Chemical Valence: Charge Transfer Effects in Coordination Chemistry. J. Chem. Phys. 2015, 142 (8), 084112.

(27) Buttarazzi, E.; Rosi, F.; Ciancaleoni, G. Influence of Halogen Bonding on Gold(i)-Ligand Bond Components and DFT Characterization of a Gold-Iodine Halogen Bond. Phys. Chem. Chem. Phys. 2019, 21 (36), 20478-20485.

(28) Ciancaleoni, G.; Belpassi, L. Disentanglement of Orthogonal Hydrogen and Halogen Bonds via Natural Orbital for Chemical Valence: A Charge Displacement Analysis. J. Comput. Chem. 2020, 41 (12), 1185-1193.

(29) Novák, M.; Foroutan-Nejad, C.; Marek, R. Asymmetric Bifurcated Halogen Bonds. Phys. Chem. Chem. Phys. 2015, 17 (9), 6440-6450.

(30) Bora, P. L.; Novák, M.; Novotný, J.; Foroutan-Nejad, C.; Marek, R. Supramolecular Covalence in Bifurcated Chalcogen Bonding. Chem. - A Eur. J. 2017, 23 (30), 7315-7323.

(31) Mitoraj, M. P.; Michalak, A. Theoretical Description of Halogen Bonding - An Insight Based on the Natural Orbitals for Chemical Valence Combined with the Extended-Transition- State Method (ETS-NOCV). J. Mol. Model. 2013, 19 (11), 4681-4688.

(32) Salvi, N.; Belpassi, L.; Tarantelli, F. On the Dewar-Chatt-Duncanson Model for Catalytic 
Gold(I) Complexes. Chem. - A Eur. J. 2010, 16 (24), 7231-7240.

(33) Bartalucci, N.; Belpassi, L.; Marchetti, F.; Pampaloni, G.; Zacchini, S.; Ciancaleoni, G. Ubiquity of Cis-Halide $\rightarrow$ Isocyanide Direct Interligand Interaction in Organometallic Complexes. Inorganic Chemistry. American Chemical Society December 3, 2018, pp 14554-14563.

(34) Ciancaleoni, G.; Belpassi, L.; Marchetti, F. Back-Donation in High-Valent D0 Metal Complexes: Does It Exist? The Case of NbV. Inorg. Chem. 2017, 56 (18), 11266-11274.

(35) Hausmann, D.; Feldmann, C. Bromine-Rich Zinc Bromides: Zn6Br12(18-Crown-6)2×(Br2)5, Zn4Br8(18-Crown-6)2×(Br2)3, and Zn6Br12(18-Crown-6)2×(Br2)2. Inorg. Chem. 2016, 55 (12), 6141-6147.

(36) Qu, Y.; Liu, Z. Di; Tan, M. Y.; Zhu, H. L. Bis[Tetraamminezinc(II)] Tetrapicrate Trihydrate. Acta Crystallogr. Sect. E Struct. Reports Online 2004, 60 (9), m1343-m1345.

(37) Cameron, E. M.; Louch, W. E.; Cameron, T. S.; Knop, O. Thiocyanates. 1: N-H(N)...S Bonding in Tetrahedral [Zn(NCS)2L]0 Complexes ( $\mathrm{L}=\mathrm{MexH} 2-\mathrm{XN}(\mathrm{CH} 2) 2 \mathrm{NH} 2-\mathrm{YMey}, \mathrm{x}, \mathrm{y}=0$ 0-2). Zeitschrift fur Anorg. und Allg. Chemie 1998, 624 (10), 1629-1641.

(38) Nithya, K.; Karthikeyan, B.; Ramasamy, G.; Muthu, K.; Meenakshisundaram, S. P. Growth and Characterization of Fe3+-Doped Bis(Thiourea)Zinc(II) Chloride Crystals. Spectrochim. Acta Part A Mol. Biomol. Spectrosc. 2011, 79 (5), 1648-1653.

(39) Marcos, C.; Alía, J. M.; Adovasio, V.; Prieto, M.; García-Granda, S. Bis(Thiourea)Cadmium Halides. Acta Crystallogr. Sect. C Cryst. Struct. Commun. 1998, 54 (9), 1225-1229.

(40) Nardelli, M.; Cavalca, L.; Braibanti, A. The Structure of Rhombic Thallous Nitrate. Gazz. Chim. Ital. 1957, 87, 137.

(41) Li, Q.; Qiu, S. C.; Zhang, J.; Chen, K.; Huang, Y.; Xiao, X.; Zhang, Y.; Li, F.; Zhang, Y. Q.; Xue, S. F.; et al. Twisted Cucurbit[n]Urils. Org. Lett. 2016, 18 (16), 4020-4023.

(42) Moloto, M. J.; Malik, M. A.; O’Brien, P.; Motevalli, M.; Kolawole, G. A. Synthesis and Characterisation of Some N-Alkyl/Aryl and N,N'-Dialkyl/Aryl Thiourea Cadmium(II) Complexes: The Single Crystal X-Ray Structures of [CdCl2(CS(NH2) NHCH3)2]n and [CdCl2(CS(NH2)NHCH2 CH3)2]. Polyhedron 2003, 22 (4), 595-603.

(43) Al-Far, R. H.; Haddad, S. F.; Ali, B. F. Three Isomorphous 2,6-Dibromo-Pyridinium TetraBromidometallates: $(\mathrm{C} 5 \mathrm{H} 4 \mathrm{Br} 2 \mathrm{~N}) 2[\mathrm{MBr} 4] \cdot 2 \mathrm{H} 2 \mathrm{O}(\mathrm{M}=\mathrm{Cu}, \mathrm{Cd}$ and $\mathrm{Hg})$. Acta Crystallogr. Sect. C Cryst. Struct. Commun. 2009, 65 (11), m451-m454.

(44) Sobhia, M. E.; Panneerselvam, K.; Chacko, K. K.; Suh, I. H.; Weber, E.; Reutel, C. Crystal Structure of the 2:1 Complex of Mercury(II) Chloride with Trithiapyridino-12-Crown-4 Having 
Unusual Mercury Coordination. Inorganica Chim. Acta 1992, 194 (1), 93-97.

(45) Canty, A. J.; Chaichit, N.; Gatehouse, B. M.; George, E. E. Coordination Chemistry of Methylmercury (II). Complexes of Aromatic Nitrogen Donor Tripod Ligands Involving New Coordination Geometries for MeHgII. Inorg. Chem. 1981, 20 (12), 4293-4300.

(46) Lee, K. M.; Chen, J. C. C.; Huang, C. J.; Lin, I. J. B. Rectangular Architectures Formed by Acyclic Diamido-Metal-N-Heterocyclic Carbenes with Skewed Conformation. CrystEngComm 2007, 9 (4), 278-281.

(47) Neese, F. The ORCA Program System. Wiley Interdiscip. Rev. Comput. Mol. Sci. 2012, 2 (1), $73-78$.

(48) Neese, F. Software Update: The ORCA Program System, Version 4.0. Wiley Interdiscip. Rev. Comput. Mol. Sci. 2017, 8 (1), e1327.

(49) Grimme, S.; Antony, J.; Ehrlich, S.; Krieg, H. A Consistent and Accurate Ab Initio Parametrization of Density Functional Dispersion Correction (DFT-D) for the 94 Elements HPu. J. Chem. Phys. 2010, 132 (15), 154104.

(50) Mitoraj, M.; Michalak, A. Natural Orbitals for Chemical Valence as Descriptors of Chemical Bonding in Transition Metal Complexes. J. Mol. Model. 2007, 13 (2), 347-355.

(51) Nalewajski, R. F.; Mrozek, J.; Michalak, A. Two-Electron Valence Indices from the Kohn-Sham Orbitals. Int. J. Quantum Chem. 1997, 61 (3), 589-601.

(52) Nalewajski, R. F.; Ozek, J. Modified Valence Indices from the Two-particle Density Matrix. Int. J. Quantum Chem. 1994, 51 (4), 187-200.

(53) Nalewajski, R. F.; Köster, A. M.; Jug, K. Chemical Valence from the Two-Particle Density Matrix. Theor. Chim. Acta 1993, 85 (6), 463-484.

(54) Altun, A.; Neese, F.; Bistoni, G. Effect of Electron Correlation on Intermolecular Interactions: A Pair Natural Orbitals Coupled Cluster Based Local Energy Decomposition Study. J. Chem. Theory Comput. 2019, 15 (1), 215-228. 